\title{
Potential Implementation of Light Steel Panel System For Affordable Housing Project In Malaysia
}

\author{
Misriyanti Saikah ${ }^{1 *}$, Narimah Kasim ${ }^{1 *}$, Norliana Sarpin $^{1}$, Hamidun Mohd Noh ${ }^{1}$, Rozlin Zainal ${ }^{1}$ \\ ${ }^{1}$ Department of Construction Management, Faculty of Technology Management \& Business, Universiti Tun Hussein Onn Malaysia, \\ 86400 Parit Raja, Batu Pahat, Johor, Malaysia
}

\begin{abstract}
The high demand-supply gap of affordable housing has been a major issue in Malaysia and has increased housing prices. A conventional method of construction is not reliable in delivering the increased demand for housing. Additionally, Industrialised Building System (IBS) faced difficulties to be implemented smoothly due to the issue related time, cost and quality. Therefore, light steel panel (LSP) system, is one of the IBS types; can be utilized in a housing construction project. This new system can replace the conventional method that was currently used in the construction of an affordable housing project. The objectives of this study are to identify the potential of LSP and the influencing factors of system implementation. Interviews are conducted with three project managers who have working experience in Syarikat Perumahan Negara Berhad (SPNB), Kumpulan Prasarana Rakyat Johor Sdn Bhd (KPRJ) and PIJ Property Development Sdn Bhd as a developer of affordable housing in Johor. Two contractors from G1 which have more than three years' experiences in implementing affordable housing project in Malaysia were also interviewed. Based on the interview, it is expected to define the potential and influencing factors of the LSP system. The findings are meaningful in framing and enhancing construction housing method of an affordable housing project in Malaysia.
\end{abstract}

\section{Introduction}

Nowadays, the construction industry in Malaysia faces pressure to fulfill the needs of affordable housing. Developers need to supply affordable housing which currently rates under RM300,000, with the lower fixed price as ranging from $\mathrm{RM} 25,000$ to $\mathrm{RM} 42,000[1,2]$. This price rate has burdened the developer and contractor to bare the rising of housing material cost.

The housing cost will remain high if the conventional construction methods are still widely used in the construction of affordable housing in Malaysia and unable to respond to the housing demand in a short time with standard quality [3]. A high number of unskilled workers are required in the conventional method of construction to complete the on-site works. The dependency of unskilled workers to carry out works will influence the time needed to complete the projects.

Industrialised Building System (IBS), also known as off-site manufacturing (OSM) technique, was introduced by the Malaysian Government in 1966. However, the usage of IBS in Malaysia by developers and contractors are still infancy. IBS is not a popular choice because of high cost, high risk and high level in setting up the programs [4]. Therefore, this study will establish the framework for improving residential construction system by utilisation of the LSP system to promote the usage of IBS in Malaysia.

The LSP can be built quickly and economically due to the installation method carried out in premanufactured which has reduced construction time and labour [5]. The installation process starts by connecting the wall framing components in a factory. The panel components then brought to the site and the labour starts joining panels using clips and self-drilling screws. These erection steps implemented with the simple procedure and will shorten the project duration. LSP systems found extensive usage, due from that this system is widely used for the construction of commercial and residential buildings with the low and moderate rise in United States, Canada, Australia, Japan, and many other countries [6].

\section{Affordable Housing in Malaysia}

To deliver affordable and quality housing, the government and private developers need to know the main factors that attracting people to buy a house, to avoid projects from becoming abandon and also to guarantee the projects being carried out will satisfy the homeowners' expectations. 


\subsection{Current Housing Construction Method in Malaysia}

In order to meet current housing need, especially for the low and middle income, the government and private sector have played their role in social responsibility in raising the effort to build the shelter for people. However, by utilizing the current construction method, the developers face difficulties to develop the affordable housing under the fixed budget rate. A conventional method of construction has been widely used in the construction of residential projects. This method involves on-site works of fabricating components, such as the installation of timber or plywood formwork and steel reinforcement [7]. The cast in-situ process is mainly conducted by unskilledworkers and the overall process is done on-site work.

In an effort to improve the housing construction method, Malaysia has allowed the utilisation of various types of IBS in an affordable housing construction project. Current IBS technology; includes precast concrete, interlocking brick, steel framing, lightweight block system, and timber framing system, are not only helping contractors and owners to reduce construction time and cost, but it would also help reduce construction waste and produce high energy efficiency buildings which result in a long-term benefit to projects [8]. The panel system is the most commonly used in the United State construction, $43 \%$ of all prefabricated homes used the light panel system [9]. Currently, there are various types of the panel in the market. The panels can be customised to use either as a structural panel or non-structural panel. The panels are planer elements used to build structural walls, floors, and roofs, loadbearing or non-load bearing enclosures, and interior partitions.

\subsection{Light Steel Panel (LPS) System Implementation}

LSP system is one of the building concepts that can enhance the current system of construction for affordable housing in Malaysia. LSP system was made of galvanised sheet steel which readily transformed onto shapes used for framing and has been utilized in the housing project for about 70 years [10]. The extensive use of light steel housing was given confidence to the several countries including the United State, Canada, Australia and Japan in utilising the technology for construction of commercial and residential buildings with the low and moderate rise [11]. LSP panel consist of several components includes C-Channel, roxul stone wool (insulator), insulated metal panel and angle finish (Figure 1).

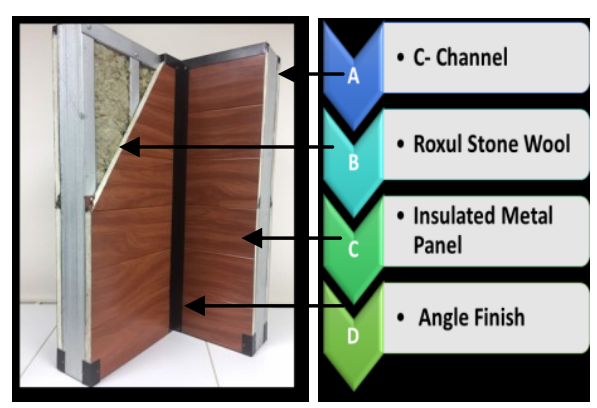

Fig 1. LSP Panel System

\subsubsection{Influencing Factors and Requirements}

Several factors influencing the implementation of LSP for affordable housing includes the regulation requirement, sustainable issues, market opportunities, social demand, economic assessment, and industrial capability. Firstly, regulation requirement involving engagement of authorities from an approval up to promotion activity for the system utilisation, such as high promotion action has been taken in China since there is a positive growth of steel in the construction industry [16].

Secondly, economies of scale in the housing construction project can be achieved by following the sustainability standard in wide-ranging criteria including economic, environmental and social aspects [17]. Thirdly, authorities must expose to the public about the factors and impacts of human activities on the environment once stimulate market demand for environmentally friendly products [13].

Fourth, one way to increase the quality of life is to supply enough housing, especially for low and middleincome earners. Lastly, all the metal stud come in precise measurement will allow easy maintenance without great material loss, contribute to fewer expenses and faster construction time, hence to obtain a greater economic performance in the life-cycle costs indicators [13].

In addition, there are three main aspects that need to concern regarding the requirement of implementation of LSP; which include technology, labour training, and investment. Technology transfer will begin with learning from foreign country experience such as Japan to achieve their highly successful manufacturing system [18]. While the initial investment to build up the manufacturing firm for LSP installation can be opened temporarily; just for project implementation purpose [19]. In order to implement the system smoothly, the manufacturing firm will collaborate with CIDB to develop the installer team and provide training for the system utilisation.

\subsubsection{Potential Implementation}

The LSP system is commonly utilised in a medium and large-scale housing project. There are many advantages of LSP including higher quality and simplicity in factory production, reliable and rapid connections system [5]. Lightweight house allowed high degrees of 
prefabrication, in which major part of houses was installed at the manufacturing firm under control production [12]. As a result, construction work becomes faster and precise steel material has further given a greater economic performance [13].

Besides that, LSP system commits simple construction method, in which the installation technique is basically as wooden framing system will give a lot of advantages to the local builder to understand the installation method [14]. LSP also fulfill the green building specification in which there are less scrap and waste from the construction process and high recyclability [13].

However, because of the LSP is a new system of IBS, there is very less theoretical analysis and nor relevant experimental data of the structure exist as a guide for local designer and architect to develop the systematic lightweight steel specification [15]. Secondly, the LSP system is very new to the people in term of structure and has low confidence in its security, stability, comfort and etc. However, the disadvantages of LSP can be solved by several actions such as technology transfer, further experimental research, and promotion. Therefore, several influencing factors and important requirements need to be aware to ensure LSP system can be implemented in an affordable housing project.

\section{Methodology}

The researches were conducted an exploratory study by utilising semi-structured interviews to examine the influencing factors and potential of the LSP system to be implemented in an affordable housing project. An indepth interview is conducted with the project managers with more than three years of working experience in an affordable housing project in Malaysia. The interviewees are from Syarikat Perumahan Negara Berhad (SPNB), Perumahan Islam Johor (PIJ) and Kumpulan Prasarana Rakyat Johor (KPRJ) as a developer's subsidiary owned by the government. Also, two contractors from G1 which have more than three years' experience to implement affordable housing project in Malaysia were being interviewed.

\section{Result and Discussion}

Respondents for this research is focused on the project manager which has more than three years of working experience in developers firm which the main project is for affordable housing. They gain experience based on the main project management principles to organize, lead, plan and control the whole project implementations process. Project manager handles the entire project includes preparation of site plan, project financing plan, manages the design and construction teams including architects, general contractors, engineers, construction managers and other consultants to ensure adherence to project budget and schedule, cost containment and quality control.
Table 1. Respondent's Detail

\begin{tabular}{|c|c|c|c|}
\hline $\begin{array}{c}\text { Respondent } \\
\text { (R) }\end{array}$ & Position & Experiences & $\begin{array}{c}\text { Affordable } \\
\text { value (RM) }\end{array}$ \\
\hline R1 & $\begin{array}{c}\text { Project } \\
\text { Manager }\end{array}$ & 8 years & $\begin{array}{c}350,000 \text { \& } \\
\text { below }\end{array}$ \\
\hline R2 & $\begin{array}{c}\text { Project } \\
\text { Manager }\end{array}$ & 5 years & $\begin{array}{c}150,000 \text { \& } \\
\text { below }\end{array}$ \\
\hline R3 & Project & 4 years & $\begin{array}{c}150,000 \text { \& } \\
\text { below }\end{array}$ \\
\hline R4 & $\begin{array}{c}\text { Manager } \\
\text { Director }\end{array}$ & 10 years & $\begin{array}{c}150,000 \text { \& } \\
\text { below }\end{array}$ \\
\hline R5 & $\begin{array}{c}\text { Managing } \\
\text { Director }\end{array}$ & 5 years & $\begin{array}{c}150,000 \text { \& } \\
\text { below }\end{array}$ \\
\hline
\end{tabular}

Table 1 shows the position, years of experiences and value of affordable housing offers by the organization. From the schedule, we know that all of the respondents in a position as a construction project manager. Experience more than three years is considered to have various experiences in the house developments project implementation. The selection of the project manager was vital to this research due to their experience involvement in planning, implement and controls the affordable housing construction project. To strengthening the result contractors from G1 with more than three years experiences in conducting affordable housing project as respondent R4 \& R5 were also interviewed.

\subsection{Influencing Factors}

\subsubsection{Construction regulation}

Rules and regulation enforced by the government are very important to the housing construction sector industry. It is in order to secure and prevent buyers from getting the low standard of housing condition at least after five years own the house. The important license for housing development is for the Uniform Building by Law (UBBL) applications of fire safety provision, Construction Industry Development Board (CIDB) approval, SIRIM and local authority (PBT). Respondent 2 (R2) shared their knowledge and experience on how to enter new housing product into the housing construction industry.

R2: "What I see here is, from my personal experience when you go to housing construction regulation, first is UBBL, CIDB, BOMBA, SIRIM and Pihak Berkuasa Tempatan (PBT). Then, Majlis Perbandaran, is commonly for authority. This is before the start of the housing project. When you are finished, you can apply CF (CCC)."

\subsubsection{Sustainable Development}

Sustainable housing development in Malaysia is still in early stage. A lack of knowledge and misunderstanding about green building concept is making it hard for the new system to enter into the market. Developers agreed that the utilisation of IBS especially hybrid system can 
reduce the environmental impacts caused by wastage from constructions project [8]. However, the implementation of the system depends on technology development.

R3: "We also have used one type of dry material, this contractor using lightweight block. The block not wet, it has a green element specification. They have two reasons why they are using this block because it can reduce almost $70 \%$ labourer work on site and very less wastage especially from the mortar."

\subsubsection{Market Opportunities}

Developers in Malaysia are willing to welcome a new system like IBS; especially in the development of low and medium cost houses with a focus in a modular pattern. This would help the developers to develop the project at a fixed price and overcome the uncertainty cost when running the project. They will satisfy if housing development could be done in low cost and faster duration time, and at the same time will give them a huge profit from the housing development [13].

R1: "Yes we can use this material. Because currently the affordable housing price is fixed and the cost price has been increasing. For example, house type A (RM42, 000) has been set by the government with fixed housing size. Because of that, we intend to use the LSP system to lower the construction cost by faster installation time."

\subsubsection{Economic Assessment}

Developers also agreed that cost is the main focus in developing affordable housing [17]. The respondent told that good cost comes together with a big house and a faster installation time.

R3: "I have been discussing IBS issue; I have been contacted by them about IBS. In the end, it spilled out of cost, the point is about of cost. Whatever, all type of IBS, whatever frame, panel system or interlocking brick which we just put in the brick-like Lego system."

\subsubsection{Industry Capability}

For the new system, Malaysia needs to implement in the closed system first. One organization needs to invest one manufacturer for LSP component manufacturing [19]. This is because the lightweight structure is not yet entered into the housing market. Then, they need a specialist to the system, to easiness the housing construction. Importantly, the manufacturer needs to fully train the supervisors to supervise workers at site works.

R2: "For implementing this, we must open the manufacturing firm, there is no problem with installation because we just need 3 peoples to install the housing component and at the same time we need a supervisor to monitor the works. It is also same as like
IBS, the first time for implementation needs a guide from the manufacturer, and then the workers will follow the method statement."

\subsection{Potential Implementation}

\subsubsection{Advantages}

LSP system will offer benefits to the contractor in terms of faster construction time and lower materials cost. It is due to the fixed price for lower and medium cost houses by the federal government to the developers. Whereas, contractors will get more profit if the housing project can be finished in a short time and fewer customers call back. This statement is supported by Andrade et. al [13], where they urged speed constructions work and precise steel material has further given a greater economic performance. Thus, the so-called "iron triangle" of time, cost and quality have been the most important metrics of construction project performance, especially for the selection of appropriate procurement methods.

R3: "For affordable housing, the main thing is the cost, because it comes at a fixed price. If we won't develop it in a fast manner, so we not call it low cost, we usually open tender to contractor and contractor will give us a lot of prices. They offer a higher price if we want the project to finish faster than usual."

R1: "As a developer, we must make sure to achieve the target for project cost, quality and time because for us we need to make a bank loan to run the housing project. The bank will start to count the interest after the money has been issued, because of that we must make sure the project must be finished faster at the optimum cost to ensure we will sell it faster so we can be gained back the money."

Contractors R4 with ten years' experience in affordable housing construction urged that increasing of cost in developing the affordable housing project not altered by material cost only. They will accept any system which is a simple, reliable and rapid connection and will shorten the project time [5]. Hence, the LSP as a light panel wall will give the easiness to the labour to join the wall panel using the screw as a connector. In fact, the contractor and labour will get more profit from the increasing number of the project done per year.

R4: “...take a long time to do a project, expose us to the risk. Whether risk for profit and loss or duration time given by developers or owner. To me, I like the materials or system which is faster to install, so that everyone will get benefits from a faster constructions time. Then we can implement the new project and can increase the quantity of housing project." 


\subsubsection{Disadvantages}

A big issue for the new housing system to be implemented in housing construction is about the operation. Construction industry plays with several hierarchies. Its start from developers open tender for the main contractor, then sub the contract to the subcontractor and sub-contractor hire the builder to finish the job. The contractor will face problems; especially to train the builders who have less exposure to utilise the new system, such as the installation system for LSP.

R2: "We have 1 project 'Mesra Rakyat', they are using interlocking brick. It is like the brick without structure. We build three units of houses at that time, the materials housing supplier have taught them how to install but when we go to the site to visit the builder, they are not properly following the step. Then, by the end of the project, a lot of problems had occurred with the house".

The contractor R5 also agreed that they faced difficulties to train the unskilled workers. Not even by using the IBS, but also for the conventional system. In fact, the new panelised system just needs to allocate the one or two expert installers to teach labours the installations method. Definitely, the installation method for LSP panel component is simpler, reliable and rapid connection system [12]. For one or two projects the expert will act as the supervising team for the LSP panel housing system installation.

R5: "If using bricks system, we need to train labours to ensure they are familiar with every steps of the process; starting from piling, tie stone, plastering, roofing, tiling, painting and so on. By using this LSH panel, you perhaps face difficulty if you don't put any skilled workers who are able to teach us to install the panel in the beginning. Definitely, by using this material it will more easy to train labour; compare to the conventional system or precast concrete because of this LSH panel system just involved one or two materials, we just need to train labour to upgrade their skills, especially in metal panel structure only."

\section{Conclusion}

This paper gives a clear understanding of the potential implementation of LSP for an affordable housing project in Malaysia. View amongst developers of affordable housing project about the proposed system is important to be a guide to the LSP implementation. Obviously, several developers have been introduced by several types of IBS, including steel framing concept. In fact, they agreed the lower cost, shorter construction time and quality housing are the main reason for the success of implementation. Therefore, several reasons, namely the target of fulfilling the housing demand, economies of scale and availability of expert LSP installer, were identified as vital in determining the success of the implementation of the LSP system for an affordable housing project.

\section{References}

1. F. Ramli, R. Zainal., M. Ali, Equilibrium Price Application Modelling for Affordable Housing Market in Malaysia. International Soft Science Conference. eISSN; 2357-1330,2016.

2. B. C. Abdullahi, W. N. A. W. A. Aziz, The Role Of Private Sector Participation in Achieving Anticipated Outcomes For Low-Income Group: A Comparative Analysis of Housing Sector Between Malaysia And Nigeria. African Journal Of Business Management, 5(16), 6859-6890, 2011.

3. M. N. M. Nawi, A. Lee, M. N. A. Azman, K. A. M. Kamar, Fragmentation Issue in Malaysian Industrialised Building System (IBS) Projects Journal of Engineering Science and Technology 9(1) 98, 2014.

4. M. S. Fathi, M. Abedi, A. K Mirasa, Construction Industry Experience of Industrialised Building System in Malaysia. 9th International Congress on Civil Engineering (9ICCE) (Iran: Isfahan University Of Technology IUT) 1, 2012.

5. S. Mashhadifarahani, Light Weight Steel Frames verses Common Building Structures - Structural Performance Evaluation Research Journal for Engineering, Technology, and Sciences (ASRJETS) ISSN (Print) 2313-4410 (Iran: Global Society of Scientific research \& Researchers) 229, 2015.

6. H. Mehdizadeh, M. Ravanshadniya, Technical and Economic Assessment of Building Performance Through Light metal Frame (LSF). International Academic Journal Of Science And Engineering (Elsevier) 4(2) (Iran: International Academic Institute for Science and Technology) 113-123, 2017.

7. N. A. Haron, I. S. Hassim, M. R. A. Kadir, M. S. Jaafar, Building Cost Comparison Between Conventional and Formwork System: A Case Study Of Four-Storey School Buildings In Malaysia. American Journal Of Applied Sciences 2(4) 819-823, 2005.

8. CIDB, Industrialized Building System (IBS) Roadmap 2003-2010 Construction Industry. Kuala Lumpur: Development Board (CIDB) (2003)

9. R. E. Smith, Prefab Architecture: A Guide to Modular Design and Construction. John Wiley \& Sons (2010)

10. R. M. Lawson, R. G. Ogden, 'Hybrid' Light Steel Panel and Modular Systems. Thin-Walled Structures 46 (7-9) 720-730, 2008.

11. H. Mirzaaghabeik, H. R. Vosoughifar, Evaluation HSE of a LSF System Subject to Near and FarField Earthquakes. Natural Science Review: 
Natural Science And Engineering 17(3) (Kokushikan: Kangnam University) 69-78, 2015.

12. O. Eren, A Comparison with Light Steel Frame Constructional Building Systems for Housing World Applied Sciences Journal 25 (3) 354-368, 2013.

13. J. B. Andrade, L. Bragança, A. Camoes, Steel Sustainability Assessment - Do BSA Tools Really Assess Steel Properties?. Journal of Constructional Steel Research. 120 106-116, 2016.

14. J. H. Hacker, J. A. Gorges, Residential Steel Design and Construction. (New York: McGrawHill Companies) (1998)

15. X. Li. J. Wang, X. P. Meng, J. Wang, Comparison and Analysis of Lightweight Steel Structure Residential Housing. International Conference on Mechatronics Control and Electronic Engineering (MCE 2014) Atlantis Press (China: Hebei Agricultural University Baoding) 720-721, 2014.

16. X, Cheng, X. Z. Zhao, Y. Y. Chen, Overall Investigation of Affordable Residential Housing in China. Proc. International Conference on Electric Technology and Civil Engineering (ICETCE) IEEE (China: Lushan) 539-543, 2011.

17. H. Corman, M. A. Curtis, K. Noonan, N. E. Reichman, Maternal Depression as a Risk Factor for Children's Inadequate Housing Conditions Social Science \& Medicine 149 76-83, 2016.

18. M. Taylor, S. Wamuziri, I. Smith, Automated construction in Japan. In Proceedings of the Institution of Civil Engineers-Civil Engineering, 156(1), pp. 34-41, 2003.

19. N. A. Azman, M. S. S. Ahamad, T. A. Majid, M. H. Hanafi, Status of Industrialized Building System Manufacturing Plant in Malaysia. UNIMAS e-Journal of Civil Engineering, 2(2), 201 